\title{
Injustiça, autonomia moral e organização escolar: análise exploratória de relações
}

\author{
Roseli Fischmann \\ Universidade de São Paulo, São Paulo-SP, Brasil
}

\begin{abstract}
Resumo: Este artigo procura analisar aspectos do solapamento da autonomia moral dos indivíduos no interior de organizações, em especial da escola, e sua relação com a construção democrática, a partir do debate da relação entre diversidade e direitos humanos, tomados como "conhecimento histórico profético", segundo Bobbio. Toma como base para propor o questionamento as relações: entre indivíduos e grupos, de acordo com Lorenz e Bobbio; entre organizações e seus membros, conforme Weber e Habermas; entre processos e práticas organizacionais e a capacidade de resistência e autonomia, segundo Kelman, Moore-Jr e Adorno. Procura explorar possibilidades para a educação, em face dessas relações, de forma a ser promotora da autonomia individual e da democracia.
\end{abstract}

Palavras-chave: Diversidade. Direitos humanos. Autonomia moral. Minorias. Educação.

\section{Injustice, moral autonomy and school organization: exploratory analysis of their relations}

\begin{abstract}
This article aims to analyze undermining aspects of moral autonomy of individuals within organizations, particularly in the school context, and its relation with democratic construction. The starting point is the relation between diversity and human rights, taken as "prophetic historical knowledge", according to Bobbio. The questioning proposed in this study is based on relations between individuals and groups, as proposed by Lorenz and Bobbio; between organizations and their members, according to Weber and Habermas; and organizational practices and processes and resistance and autonomy abilities, according to Kelman, Moore-Jr and Adorno. In view of these relations, it seeks to explore education possibilities towards the promotion of individual autonomy and democracy.
\end{abstract}

Keywords: Diversity. Human rights. Moral autonomy. Minorities. Education.

\section{Injusticia, autonomía moral y organización escolar: análisis exploradora de relaciones}

Resumen: Este artículo procura analizar aspectos del solapamiento de la autonomía moral de los individuos en el interior de organizaciones, en especial de la escuela y su relación con la construcción democrática, desde el debate de la relación entre la diversidad e los derechos humanos, considerados como "conocimiento profético", segundo Bobbio. Tiene como bases, para proponer el cuestionamiento, las relaciones: entre individuos y grupos, de acuerdo con Lorenz y Bobbio; entre organizaciones y sus miembros conforme Weber y Habermas; entre procesos y prácticas organizacionales y la capacidad de resistencia y autonomía segundo Kelman, Moore-Jr y Adorno. Trata de explorar posibilidades para la educación, en respecto a esas relaciones, de modo que pueda ser promotora de la autonomía individual como también de la democracia.

Palabras clave: Diversidad. Derechos humanos. Autonomía moral. Minorías. Educación. 
Os acontecimentos mundiais a partir do ataque às Torres Gêmeas em Nova York, em 11 de setembro de 2001, têm demonstrado duas forças propulsoras antagônicas, convivendo no interior de grupos humanos e a decorrente gravidade da busca de alternativas. $\mathrm{O}$ caso de imigrantes vivendo em países economicamente desenvolvidos é exemplo paradigmático da situação: por um lado não são aceitos por sociedades que os recebem como mão-de-obra (porque deles necessitam), mas não lhes reconhecem plena cidadania, a qual reivindicam, obviamente, pela contribuição econômica que oferecem - e por isso não pensam em se evadir; por outro lado, mesmo convivendo nessas sociedades, não reconhecem seus valores culturais dominantes, entendendo que podem oferecer a contribuição econômica a que se dispõem, mas sem assimilar o que freqüentemente contraria seus princípios - e, por isso, obviamente não pretendem se adaptar.

Entre os caminhos do evadir-se/expulsar e assimilar-se/dominar, surgiram novas formas de violência, para os quais, a nosso ver, não se dispõe ainda de referencial que permita compreender o que está se passando efetivamente, de forma semelhante ao que afirmou Hannah Arendt (1998) acerca dos totalitarismos que o século XX viveu. Essas novas formas de violência lançam questões que, se é verdade que antes existiram, cada vez mais assumem tom dramático frente à situação mundial, com relação ao uso da violência tanto por parte dos que se propõem a resistir às ingerências externas, como por parte dos que se propõem ao que vêem como "missão civilizatória" - ambos apontando no outro a prática da injustiça. Freqüentemente a ação individual tem determinado, nesses casos, encaminhamentos dramáticos, seja no caso de atentados suicidas, praticados em nome da vida, seja no caso de aplicação de tortura por parte de forças militares, que se propõem como sendo de liberação. Como trabalhar o tema da autonomia moral e da injustiça nesse contexto que, sendo mundial, tende a tocar o local? Qual a relação com a escola, em particular pensando sua dimensão organizacional? Vale lembrar que, entre grupos que se digladiam, a perda irreversível de vidas civis tem se dado em escala alarmante, assim como a formação reiterada de mentalidades marcadas pela discriminação de outros que se constituam como "diferentes" do padrão hegemônico. Tomando a educação escolar como centro de interesse, este artigo procura, assim, dirigir essas questões para a temática da relação entre diversidade e direitos humanos; entre indivíduos e grupos; entre membros e organizações; entre práticas organizacionais e autonomia; entre educação e entrelaçamentos dessas relações.

\section{Diversidade e direitos humanos}

$\mathrm{Na}$ história da humanidade, o jogo de submeter o estrangeiro tem marcado um padrão de comportamento em relação aos que são tomados como "o Outro", mesmo havendo casos de grupos que receberam "estranhos" de forma cordial e acolhedora - sendo notável o caso de grande parte dos indígenas nas Américas, em sua recepção aos colonizadores. Por diversas vezes na história, a derrota em uma guerra significou, para os derrotados, a vivência da escravidão como conseqüência, reconhecida e legitimada como parte das conseqüências da guerra. Por processos que aqui não são tratados por extrapolar o foco deste trabalho, a escravidão veio a ganhar tal aceitação, que sua mercantilização implantou-se de maneira sistemática a ponto de ter ou não ter escravos e em que quantidade, era tomada como indicador e elemento de prestígio social. Nem isso, contudo, impediu que a expansão da consciência humana viesse a reconhecer que a escravidão é eticamente inaceitável (Moore-Jr, 1987) e, hoje, mais ainda, encarada como crime, pela legislação nacional e internacional. Mas foi longo o percurso, não atingindo por igual mentalidades e indivíduos, tanto que a luta contra o trabalho escravo ainda é hoje uma pauta importante em nível mundial.

Exacerbada a desigualdade entre indivíduos e grupos humanos, as guerras do século XX recolocaram o tema da dominação entre Estados, assim como a retomada intensa e dramática de lutas internas, por motivos étnicos e/ou religiosos, e ainda a luta pela hegemonia sobre territórios, na definição de fronteiras (Arendt, 1989).

A Segunda Guerra Mundial deixou - com a barbárie do Holocausto, bem como com Nagasaki e Hiroshima - o terrível registro recente de até onde o ser humano é capaz de chegar na negação do Outro, por meios diversos. Foi em busca de evitar a extinção da humanidade por si mesma, que, ao término da Se- 
gunda Guerra, ocorreu a criação da Organização das Nações Unidas em 1945, e três anos depois, a promulgação da Declaração Universal dos Direitos $\mathrm{Hu}-$ manos. Era o gesto de afirmação de valores universais, de uma agenda planetária comum. Era a forma, também, de articular questões referentes às relações entre os Estados-Membros, com a ONU, e cuidar também dos indivíduos, para que não fossem preteridos pelas grandes questões políticas e econômicas (Fischmann, 2001). Contudo, como já indicado por autores como Celso Lafer (1988), a enunciação dos Direitos Humanos tem se feito, comumente, após a constatação de sua violação; ora, parece que essa característica reativa propõe uma pauta à educação no sentido de desenvolver seres humanos que não apenas sejam capazes de incorporar os diversos ganhos e avanços da consciência humana, como, mais ainda, possam resistir à prática de toda injustiça seja a que venham porventura a ser ameaçados de sofrer, seja a que estaria a seu alcance praticar.

Outro aspecto é trazido por Norberto Bobbio que em suas análises demonstra que o Universal desses Direitos refere-se, de fato, a certas circunstâncias históricas, não sendo genéricos e permanentes. Dessa forma, Direitos enunciados na citada declaração universal, já foram reformulados, complementados com novos processos de tomada de consciência (Bobbio, 1992). Resta, contudo, a dramática (embora corriqueira e banalizada) situação de que aos direitos proclamados não correspondem direitos vividos e, sequer, garantidos.

Intimamente ligados à questão da democracia, esta problemática da ausência de garantias pede que a discussão seja sempre mais especificamente localizada, situando-a em certo território geopolítico, em determinado momento histórico. Ou seja, trata-se de compreender como se manifesta e se reconstrói o universal em diferentes tempos e lugares, das grandes questões políticas ao cotidiano. Contudo, a distância entre o proclamado e o vivido, seja nos planos das diversas nações, seja no plano de esforços de nível mundial em prol dos Direitos Universais, traz a sensação de que a humanidade de fato não avançou, e que dificilmente poderíamos ter qualquer expectativa de estabelecimento de um mundo justo e livre, portanto mais aproximado da paz, que seria o objetivo de fato almejado pela comunidade mundial. Com isso, as próprias bases da prática educacional ficam questionadas, porque caberia indagar se Estados nacionais em conflito ou grupos organizados em torno da resistência violenta poderiam propiciar ou apoiar propostas educacionais no sentido de focalizar as possibilidades individuais de desenvolvimento e autonomia. Ou se, de forma mais consistente com períodos ameaçadores, praticariam a mera transmissão de doutrinação e de dogmatismo, como caminhos de sustentação do Estado ou do grupo, homogeneizando os educandos e anulando suas singulares possibilidades de desenvolvimento.

Bobbio, desdobrando o debate da relação entre universal e particular no campo dos direitos humanos, entrelaça a discussão referente à paz mundial com a referente à miséria. Assim, traz certo tipo de inconsistência que freqüentemente se pratica. $\mathrm{Ou}$ seja, a temática da paz mundial freqüentemente é encarada como questão distante por países que não se encontram em territórios conflagrados ou de alguma forma envolvidos em conflitos bélicos. Ao mesmo tempo, a questão da miséria tende a ser vista como sendo distante dos países desenvolvidos, que encaram o tema muitas vezes apenas do ponto de vista de "auxílio internacional" ou humanitário.

A abordagem de Bobbio então é no sentido de indicar que são ambas - paz mundial e miséria - partes constituintes da temática dos Direitos Universais Humanos ${ }^{1}$ :

A efetivação de uma maior proteção dos direitos do homem está ligada ao desenvolvimento global da civilização humana. É um problema que não pode ser isolado, sob pena, não digo de não resolvê-lo, mas de sequer compreendê-lo em sua real dimensão. Quem o isola já o perdeu. Não se pode pôr o problema dos direitos do homem abstraindo-o dos dois grandes problemas de nosso tempo, que são os problemas da guerra e da miséria, do absurdo contraste

\footnotetext{
${ }^{1}$ Nesse sentido, a escolha de Muhammad Yunus e o Banco Grameen, do qual é fundador, como agraciados com o Prêmio Nobel da Paz em 2006 bem expressa o avanço na compreensão desse necessário entrelaçamento da temática da paz e da miséria. (Ver http://nobelprize.org/nobel_prizes/peace/laureates/2006/).
} 
entre o excesso de potência que criou as condições para uma guerra exterminadora e o excesso de impotência que condena grandes massas humanas à fome. Só nesse contexto é que podemos nos aproximar do problema dos direitos com senso de realismo. Não devemos ser pessimistas a ponto de nos abandonarmos ao desespero, mas também não devemos ser tão otimistas que nos tornemos presunçosos (Bobbio, 1992, p. 45).

Assim, se a intolerância contra as minorias foi levada ao extremo no caso do Holocausto, tornandose a dolorosa pedra de toque que impulsionou, naquele momento, à busca da elevação da humanidade a um novo patamar de consciência frente a si mesma, ainda muitos são os caminhos que a consciência humana precisa trilhar até viver um mundo efetivamente pacífico, no sentido de Aron (1986), de paz de satisfação. A educação tem o que oferecer nessa direção, tanto quanto tem o que temer, se forem mantidas como sua base simplesmente as condições em que se atua nos outros campos sociais.

\section{Indivíduos e grupos}

Konrad Lorenz (1988) oferece-nos um dos possíveis caminhos, ao defender a importância da educação na transformação do destino humano. Sendo um evolucionista, explicita a situação alarmante da espécie humana, quando se analisa o rumo de evolução demolidora que escolheu. De fato, ao contrário das demais espécies que se valem de seu diferencial para alcançar o aperfeiçoamento e resistirem aos desafios ambientais, a humanidade tem se valido desse diferencial - a capacidade de teleologia, a linguagem verbal e a capacidade de conferir sentido às coisas para desenvolver modalidades de competição intraespécie, que, de forma lenta e certa, colocam-nos na direção da hecatombe. Estaria, então, a humanidade condenada à sua própria destruição? Haveria algo que pudéssemos fazer por nós?

Enquanto alguém que se dedica à ciência, Lorenz afirma que não tem interesse em fundamentar teologicamente a esperança. Entende que não há porque apelar a qualquer divindade em um assunto especificamente da alçada humana ${ }^{2}$. Lembra Lorenz que há um caminho que se faz no campo especificamente racional, com caráter universal, quando nos lembramos da imprevisibilidade como característica humana. Assim, há a possibilidade de que as mais catastróficas previsões, operadas com base em probabilidades, desmoronem frente ao imprevisível comportamento humano. A direção de destruição empreendida por mentes e mãos humanas, pode ser revertida da mesma forma. Na perspectiva de Lorenz, mesmo sem o apoio da fé ou da esperança de fundo teológico, pode-se, portanto, acreditar que a humanidade tem oportunidades de melhoria e transformação da situação atual frente a si mesma, tendo em conta a imprevisibilidade humana.

Já Norberto Bobbio avalia que o conhecimento histórico profético, como denomina, se faz com base nos patamares alcançados pela humanidade em termos de consciência - e nesse sentido, a mera existência da Declaração Universal dos Direitos Humanos demonstra a capacidade de diferentes povos e nações de aceitarem uma agenda comum. Mais do que discutir os fundamentos dos Direitos Humanos, legitimados exatamente por essa aceitação ampla e irrestrita, o que Bobbio propõe, então, é a busca da proteção e garantia do que já se proclamou.

Contudo, quais os principais desafios que se colocam para a ação de caráter tipicamente educativo, aquela que pode tornar possível reverter perspectivas de catástrofe, tomando como base a plasticidade, a mutabilidade e imprevisibilidade humanas? Lembremos, inicialmente, de algumas características exclusivamente humanas, como são a teleologia e a intencionalidade (Lorenz, 1988).

A teleologia como capacidade humana tem um caráter fundador, do ponto de vista da possibilidade de progresso moral. Teleologia que, unida à intencionalidade, permitirá caracterizarmos o ser humano como sendo diferente dos demais animais.

Nessa constatação inicia-se uma primeira fase do percurso de limitações ao ser humano. Bobbio (1992) lembra que a cada fatia conquistada de poder, corresponde uma fatia perdida de liberdade. Quanto

\footnotetext{
${ }^{2} \mathrm{O}$ citado posicionamento de Lorenz concorda com as teses de defesa da laicidade do Estado e da escola pública, como também defende esta autora.
} 
mais poder, menos margem de liberdade de ação, pela responsabilidade trazida pelo poder. Ora, tendo mais poder que os demais animais, o ser humano encontra-se em uma situação de responsabilidade para com os demais seres da natureza - o que traz, aqui, por exemplo, como aplicação imediata, a importância da perspectiva ambientalista do ponto de vista educacional. Já Marcuse (1982) apontava como parte de um programa revolucionário a adoção de um comportamento fraterno para com a natureza, a quem teríamos então como parceira, possibilidade que serviria de alternativa à suprema valorização do homo faber, pela racionalidade instrumental e estratégica. Referindo-se a essa proposta de Marcuse, diz Habermas:

"Só se os homens pudessem se comunicar sem coação e se cada homem pudesse reconhecer-se no outro, só então a espécie humana poderia eventualmente reconhecer a natureza como um outro sujeito - não a natureza como o seu outro, como pretendia o idealismo, mas a si mesma como o sendo o outro desse sujeito" (1975, p.308).

\section{Organizações e seus membros}

É interessante tomar essa proposta de Bobbio, da relação entre ganho de poder e perda da liberdade, para se analisar o que se passa no âmbito das organizações burocráticas e em particular da escola.

Quando se fala em burocracia, dentro da proposta weberiana de tipo ideal (Weber, 1982), uma série de atributos e características é dada: hierarquia, normas, impessoalidade, apenas para citar algumas daquelas que mais são citadas na literatura educacional.

Propostos em nome da racionalidade, freqüentemente esses atributos e características são motivo de comportamentos que nada têm de racionais. Um exemplo eloqüente e célebre foi a alegação dos carrascos nazistas, durante o julgamento de Nuremberg, de que seriam inocentes quanto às acusações de genocídio dos judeus porque apenas cumpriam ordens.

A existência de normas, necessariamente limitadas a situações previsíveis e o que se apresenta como hiperestesia por parte da hierarquia, ao tomarse como valor em si, dificultam que a hierarquia e suas normas percebam-se em seu caráter instrumental, como meio em prol da organização - e não como se configura freqüentemente, a de apresentarem-se como fim em si mesmas, a serviço da dominação de indivíduos, uns sobre os outros. Da mesma forma, certa interpretação distorcida da impessoalidade pode facilitar processos de desresponsabilização de quem domina em atos arbitrários que cometa. Ou seja, essas características, entre outras, concorrem para que a organização burocrática transforme-se de instrumental aglutinador dos esforços humanos em descaracterizadora do potencial humano, em particular em termos de teleologia, intencionalidade, autonomia (Fischmann, 1998; Kelman \& Hamilton, 1989).

Habermas (1975) chama a atenção para como se estabelecem bases desiguais, sobretudo em relações de direito privado, sob a égide da atividade capitalista, particularmente sob alegação de suposta reciprocidade e isonomia. Essa desigualdade fundamenta a prática de injustiças, ao mesmo tempo em que apóia em uma fusão da técnica com a dominação.

Do ponto de vista burocrático, há princípios organizacionais que se definiram historicamente independentemente de elaboração teórica, manifestando-se diretamente em práticas organizacionais de instituições que bem representam o tipo ideal weberiano de burocracia, como a Igreja e o Exército, as quais vieram a servir como casos exemplares de onde depreender aqueles princípios propostos por Weber (1982).

A análise da transição de sociedade tradicional para sociedade moderna freqüentemente incorpora o conceito de racionalização como uma das chaves dessa transição, onde a dominação não mais se fundamenta em princípios cosmológicos, míticos, mas no agir racional com-respeito-a-fins, e, também, na definição estratégica da racionalidade das relações meio-fim.

No estudo citado de Habermas, interessa-nos de forma particular a análise da origem da ambigüidade do conceito de racionalização ali apresentado, que propicia relacioná-lo a Lorenz.

Tratando do agir racional-com-respeito-a-fins, Habermas discute o estabelecimento de um modelo de desenvolvimento sócio-cultural onde "um crescente poder de manipulação técnica sobre as condições externas da existência" (Habermas, 1975, p.328) tem representado uma forma de adaptação ativa, voltada para a autoconservação. Em oposição, "as modificações do quadro institucional, na medida em que são imediata ou mediatamente redutíveis a novas 
tecnologias ou estratégias aperfeiçoadas (...), não receberam uma forma semelhante de adaptação ativa" (Habermas, 1975, p. 328), obedecendo, de fato, ao modelo de adaptação passiva.

Como aqui retomamos um paradigma evolucionista, voltemos a Lorenz. É dele a consideração de que até mesmo essa adaptação ativa às condições externas tem significado uma atitude predatória do ser humano em relação às demais formas de vida sobre o planeta. Contudo, se, por um lado o domínio de técnicas e criações tecnológicas humanas tem representado a adição de uma possibilidade de melhoria potencial de condições de vida, em relação à condição "natural", configurando adaptação ativa, por outro lado esse mesmo domínio não se reflete em condições favoráveis e melhores para todos.

Observe-se que na argumentação de Habermas acerca de uma adaptação passiva da humanidade em relação ao quadro institucional, poderia haver uma hipótese benéfica, de que tem faltado atenção do ser humano às condições de convivência com seus semelhantes, deixando-as ao acaso. $\mathrm{O}$ ponto que se discute, contudo, é como essas técnicas e tecnologias trazem novas formas de dominação do ser humano embutidas - ou seja, como as próprias mudanças no quadro institucional podem ser reduzidas a novas tecnologias ou estratégias que conduzam a ter cada vez mais dominação e cada vez menos participação consciente e intencional dos indivíduos nos grupos, dos membros nas organizações.

Valeria a pena lembrar que, considerando as condições materiais em que vivem amplas parcelas da população - no mundo e, em particular, no Brasil - cabe levantar uma discussão de ordem ética acerca da natureza do chamado progresso humano. É impossível - até por evidências empíricas - reduzir a discussão sobre a desigualdade, a miséria e a exclusão a certo tipo de adaptação passiva, o que seria excessiva e impropriamente generoso para com os que praticam a exclusão sistemática, particularmente considerando o potencial destrutivo presente na condição humana, como foi antes tratado.

Se é verdade que se registra intencionalidade no tratamento técnico das relações humanas, é também certo que há um papel específico desempenhado por certa adaptação passiva às configurações do quadro institucional de que fala Habermas. Trata-se de como se produz e reproduz, no cotidiano, dentro das mais diversas organizações e instituições, a legitimação desse quadro excludente, pela situação de submissão. Trata-se daquela situação a qual estão submetidos - e também à qual se deixam submeter inumeráveis contingentes humanos. É também parte do processo no qual se revesam, se compõem e recompõem o instituído e o instituinte nas organizações (Castoriadis, 1982).

\section{Processos e práticas organizacionais, resis- tência e autonomia}

As organizações humanas são caracterizadas por sua pertinência às culturas com as quais se vinculam. A cosmologia fundadora de uma cultura traz embutida a fundação e os princípios da organização social que alimentará seus mitos e cumprirá seus ritos. O que caracterizam, entretanto, processos organizacionais de cunho burocrático, é que se estruturam de uma forma que poderíamos chamar de asséptica - ao mesmo tempo em que se voltam para racionalizar o trabalho conjunto de seres humanos, fazem-no com uma estrutura básica e genérica, supostamente atemporal.

Ao mesmo tempo, o caráter instrumental dos diversos postos de trabalho, assim como os vínculos de autoridade, fica claro, quando os mesmos são propostos como se fossem "desencarnados", por assim dizer, de todo e qualquer ser humano. São voltados para tarefas e funções que deverão ser cumpridas, independentemente das pessoas que ocupem os cargos aos quais se referem, e independentemente da possibilidade de alteração das circunstâncias presentes quando de seu momento fundador. É o processo pelo qual, por independerem de pessoas, os cargos propiciam que seus ocupantes sejam vistas e tratadas como descartáveis, embora nem sempre o percebam, ainda que reproduzindo em relação aos subordinados a mesma dinâmica.

Cria-se, assim, um processo que independe de pessoas, embora seja desenvolvido por elas, e a legitimidade de ocuparem determinado lugar na estrutura burocrática será tão somente vinculado a determinações regimentais, estatutárias, em suma, a legitimidade será derivada exclusivamente da autoridade le- 
gal. Não se coloca a expectativa de representatividade, nem a de compromisso ético ou moral, posto que a margem de escolha livre é mínima ou inexistente, porém apenas se professa a eficácia e a eficiência administrativa: cumprem-se ordens.

Essa estruturação e atribuições administrativas correspondem a práticas caracterizadas pela despersonalização. Importa a tarefa a ser realizada, de forma obediente, seguindo determinações superiores. Na ausência desse cumprimento, dispõe-se de mecanismos de punição, já previstos e normatizados, freqüentemente ocorrendo de aspectos formais serem priorizados em detrimento dos substanciais.

Barrington Moore-Jr lembra que é necessário haver normas básicas, que sobrevivam à necessidade de a sociedade estar refazendo a cada vez seu contrato social. A obediência a tais normas constituise, nesse caso, um gesto de maturidade, pela adesão aos valores da sociedade específica em que se vive (Fischmann, 2001). Vale aqui lembrar, contudo, que a construção democrática significa a possibilidade de buscar em comum, por meio do debate em espaço público, aberto a todos, a transformação da norma/ legislação que não mais se apresenta como adequada à democracia. Haveria, aqui, incluídas na normatização e no contrato, formas previstas de coerção social, assim como de punição, consideradas por todos como justas.

Por outro lado, a opressão e a injustiça podem surgir tanto no âmbito de grandes embates sociais, vinculados a uma ordem social que tenha se estruturado de forma injusta, como no âmbito do cotidiano, por exemplos em ambientes profissionais - e a escola é um desses ambientes profissionais que podem estar sob ameaça de praticar e sofrer injustiças. São como rupturas do contrato social, frente à qual é próprio da maturidade não mais obedecer, mas resistir. É claro que sempre que se tratam de grandes questões sociais, essa resistência ganha legitimidade e publicidade, o que, se não diminui a injustiça, auxilia a vencê-la. Contudo, é mais difícil e complexo oporse à injustiça que é sofrida de forma particular e individual. Moore-Jr destaca, então, que o perigo está nas sociedades nas quais se encontraram formas de controlar toda resistência, nas quais a injustiça é vista como inevitável, e, portanto, sufocam-se, na base, toda indignação e ira moral geradas pelo sentimento de injustiça. No caso da educação, no microcosmo da escola, o mesmo pode ser verdadeiro, havendo escolas em que o debate é promotor da educação, enquanto em outras, poderá ser o caso em que sufocam a capacidade de expressão do sentimento de injustiça.

Mais ainda, com freqüência desenvolvem-se argumentos de justificação da situação, como indicativos de experiências de auto-anulação (como por exemplo as afirmações de "foi assim porque eu mereci o que me aconteceu" ou "não valho tanto para que se preocupem comigo"), ao lado de certo "orgulho na resignação" (Moore-Jr, 1987, p.96), que de fato é estratégia para tornar tolerável a vida, em meio a todo controle e solapamento de resistência. Se para adultos essa experiência traz problemas graves - e aqui vale também lembrar os trabalhos de Goffman (1988), como Adorno, Frenkel-Brunswik, Levison e Sanford (1950) - para a vivência em escolas que trabalham com crianças e adolescentes, mais alarmante pode ser o ambiente organizacional criado pelo solapamento do sentimento de injustiça.

É, sobretudo, frente a ordens injustas ou a uma ordem opressiva que se revelam a autonomia moral e a coragem moral, centrais como tarefa a ser assumida pela educação.

Barrington Moore-Jr identifica três qualidades da autonomia moral:

A primeira qualidade pode ser chamada de coragem moral, no sentido de uma capacidade de resistir a poderosas e ameaçadoras pressões sociais para a obediência a regras ou ordens 'opressivas' ou 'destrutivas'. A segunda qualidade é a capacidade intelectual para reconhecer que as regras e as pressões são de fato opressivas. (...) A terceira capacidade, a inventividade moral, é mais rara (...). É a capacidade de criar, a partir das tradições culturais vigentes, padrões historicamente novos de condenação ao que existe (1987, p.136).

Tratando dos efeitos do poder de pressão do grupo sobre o julgamento expresso por um indivíduo, Moore-Jr enfatiza que "um único aliado pode fornecer suficiente apoio para capacitar uma pessoa a 
elaborar um julgamento correto" (Moore-Jr, 1987, p. 139). Moore-Jr enfatiza, na seqüência de sua argumentação, que há boas razões para se considerar que o inverso também ocorra, ou seja, que basta um único apoio para que um julgamento incorreto seja consolidado - e, na situação escolar, exemplos não faltam de estigmatização de estudantes como resultado de uma única situação que poderia ser considerada inadequada ao contexto escolar; ou nem mesmo isso, apenas uma escolha daquele que é tomado como a "vítima" do momento, muitas vezes a partir de categorias previamente escolhidas como as de possíveis vítimas ${ }^{3}$.

Entre outras conclusões do longo e denso estudo de Barrington Moore-Jr (1987), a capacidade de identificar a opressão e a injustiça é tratada como sendo central na busca da construção de uma situação social que se não consegue se implantar pronta e definitivamente como justa, pode ser proposta como a construir-se de forma mais justa a cada vez. Da mesma forma, propõe Moore-Jr (1987), como parte de um fazer histórico, o desenvolvimento do sentido de inevitabilidade como sendo ilusório - ou seja, a compreensão de há certas condições desumanas, dolorosas ou degradantes das quais não se necessitam, não se podem e não se devem suportar. Certo conformismo na dor e no sofrimento, muitas vezes com justificativas de tipo religioso, acaba servindo à paralisação de possibilidades individuais, sociais e históricas. A reversão do sentido de inevitabilidade significa, portanto, que as pessoas possam compreender que a dificuldade na alteração de certa situação dolorosa vigente

\footnotetext{
${ }^{3}$ Ver, a esse respeito, Kelman (1973). No caso, o debate tem particular relevância para normas institucionais que facilitam o surgimento do que é denominado por Kelman como "categorias sancionadas de vítimas", ou seja, cria-se uma aceitação e consenso (às vezes tácito) de quais são aquelas categorias de seres humanos que podem ser considerados menos humanos, ou nem bem humanos, que ficam, com isso, mais sujeitos a ataques à sua dignidade, a qual sequer é reconhecida. A inspiração de Kelman é o que se passou no Holocausto, mas estende a base de sua análise a situações criadas por práticas racistas em geral, a questões de tratamento de prisioneiros de guerra ou a civis que se encontram em campo inimigo, ou ainda pessoas que são sujeitas a torturas. Sem dúvida as repercussões para esse tipo de conceito de "categoria sancionada de vítima" para a escola e a educação de maneira geral tem grande potencial e integra um dos focos analíticos de pesquisa que se encontra em desenvolvimento sob responsabilidade desta autora.
}

não significa que a mesma integre a ordem "natural" das coisas, sendo por isso inevitável, mas que essa dificuldade talvez diga respeito a outras dificuldades, como tradições arraigadas ou outros interesses, que não a melhoria da qualidade da vida humana. Mudar o sentido da irreversibilidade é central no trabalho da escola e há de se fazer não apenas na análise das conquistas humanas e democráticas, mas como vivência cotidiana.

Nesses processos pelos quais se desenvolve a capacidade de identificação da opressão e da injustiça, e de solapamento do sentido de inevitabilidade, a informação desempenha papel relevante, assim como o debate aberto e esclarecido (Adorno \& Horckheimer, 1985), que possa servir como o apoio social de que tratou Moore-Jr (1987), capaz de fortalecer o discernimento facilitador do sentimento de injustiça, dando suporte à capacidade de resistência.

Neste ponto evidencia-se a relevância da escola, não apenas como fornecedora de informação, mas como facilitadora de processos que conduzam à formação da capacidade crítica, bem como de habilidades de expressão de opinião e, sobretudo, de resistência à opressão. Voltemos ao estudo de Habermas anteriormente citado. Texto surgido em meio aos ares revolucionários de 1968, Habermas explicita, ali, sua certeza de que apenas a crítica das ideologias burguesas é que torna possível que entre no domínio da consciência pública a incongruência citada, entre adaptação ativa e adaptação passiva da humanidade.

Arriscando alguma prospecção, traz à lembrança repertório de técnicas de controle de comportamento e modificação de personalidade listado por Hermann Kahn como aquelas que estariam prestes a ocorrer, para afirmar que somente:

A discussão pública, que não sofre restrições e que é isenta de dominação, sobre a adequação e a conveniência de princípios e normas que orientam o agir à luz dos reflexos sócio-culturais dos subsistemas progressivos do agir racional-com-respeitoa-fins - apenas uma comunicação dessa espécie, em todos os níveis dos processos políticos e repolitizados de formação da vontade, é o único meio no qual algo como uma 'racionalização' é possível. Num tal 
processo de reflexão generalizada, as instituições seriam modificadas na sua composição específica para além dos limites de uma mera mudança de legitimação (Habermas, 1975, p.331).

Exemplos de desenvolvimento intencional dessa consciência pública estão presentes quando conseguimos, como educadores, operar intersecções com colegas de outras áreas, assim como com movimentos sociais, ou mesmo setores governamentais. Da mesma forma, a cooperação com a imprensa se coloca nesse nível de importância, tanto no que se refere a acadêmicos que possam interagir como fontes e como debatedores dos temas em questão, como por parte da escola básica, que poderá tomar publicações da mídia como subsídio e conteúdo de aprendizagem, assim como prática de crítica e interação na esfera pública.

A citada análise de Habermas teve grande importância quando de sua publicação, mas parece que cada vez mais se renova essa relevância, pensando sobre as novas formas de racionalidade impostas por padrões estabelecidos em nome da qualidade. Da mesma forma é agudizada sua análise, quando podemos comprovar que a última década, em particular, assistiu a um afluxo de interesse e atenção à questão da modificação do quadro institucional, porém não na direção pretendida por Habermas, mas exatamente em seu oposto.

Ou seja, ao invés de caminharmos, como humanidade, em direção a uma consciência pública das formas e processos de interação institucional, fundada em um conhecimento objetivo do que se faz e sedimentado em uma postura crítica, caminhamos muito mais evidentemente em direção às previsões de Hermann Kahn, rumo a uma "alienação planejada", ou, uma situação na qual, nas palavras de Habermas, "os homens fariam a história com vontade, mas não com consciência" (Habermas, 1975, p. 330).

Dentre as possibilidades de ação que se abrem nesse contexto, em busca da construção de uma sociedade que recupere e mantenha a possibilidade da liberdade, é preciso encontrar aquelas para as quais a questão não seja garantir a geração de legitimidade, que se constrói de maneira artificial, da ordem do simulacro, por sobre uma legitimidade verdadeira que se debilita e esfacela. Nestes casos, poderá ocorrer uma suposta conquista de igualdade, porém uma igualdade repressiva, de iguais na injustiça (Adorno \& Horkheimer, 1985).

O que se coloca, sim, é a substancialidade de ações em direção à construção da igualdade, fundada na justiça, que se configura como emancipatória, frente ao quadro de dominação consolidado pela técnica e pela burocracia, freqüentemente auxiliadas pelo concurso da ciência.

Trata-se, também, de efetivar um levantamento de quais as possibilidades históricas que estão hoje de fato presentes, de forma a construir um projeto social viável, que, enquanto se elabora, já se efetiva empiricamente. É um sentido diverso de utopia (não sendo contraditório), pois se trata de identificar, dentro do campo de possibilidades, aquelas que estão efetivamente disponíveis. Elevar a consciência guarda relação com essa atividade, a fim de que não nos entreguemos à resignação de uma adaptação passiva, onde possibilidades sejam suprimidas historicamente, sem que tenhamos nos dado conta delas, a não ser quando já seja tarde (Moore-Jr, 1987).

Nesse sentido, é crucial discutir a natureza das práticas organizacionais e administrativas, que se proponham como práticas despersonalizantes e que, portanto, afrontam a dignidade humana no âmbito das organizações sociais, nas quais, em primeira instância, o indivíduo deveria conviver com a justiça e com a possibilidade de mudar, vivência que deve se fazer, portanto, longe da sombra ilusória e opressora do inevitável, se o que se pretende é a democracia e o respeito aos direitos humanos como construção cotidiana (Fischmann, 1998), para o que cabe a escola, em todos os níveis, tem papel indispensável a desempenhar.

Assim, se a escola já tem muito com o que se preocupar, no que se refere a práticas e procedimentos pedagógicos, isso não a isentará de encarar uma tarefa indispensável e crucial, de pensar o solo em que assenta o pedagógico. Genericamente chamado de "administrativo", jamais dará conta da gama de questões e tensões que formam o "organizacional", a partir do qual efetivamente podem-se pensar relações humanas, promotoras do material mais substancial de que se faz a educação, e não concretizações de organogramas, que escondem siglas e referências funcionais, indicando talvez interesses imediatos, como 
os que são dados pela remuneração ou status de postos de autoridade, mas jamais sustentaram o trabalho educativo no que tem de mais essencial. É por isso que a temática da diversidade e da pluralidade humana são tão relevantes para a educação, porque oferecem caminho imediato de ir ao "encarnado" da questão, ali onde ela se coloca de forma mais complexa e mais dramática: na exclusão e no abandono da dignidade humana.

\section{Referências}

Adorno, T. W., Frenkel-Brunswik, E., Levison, D. J., \& Sanford, R. N. (1950). The authoritarian personality. New York: Harper and Brothers.

Adorno, T., \& Horkheimer, M. (1985). Dialética do esclarecimento (2a ed.). Rio de Janeiro: Jorge Zahar.

Arendt, H. (1989). Origens do totalitarismo: Antisemitismo, imperialismo, totalitarismo. São Paulo: Companhia das Letras.

Arendt, H. (1998). The human condition (2th ed.). Chicago, IL: The University of Chicago Press.

Aron, R. (1986). Paz e guerra entre as nações (2a ed.). Brasília, DF: Editora da UnB.

Bobbio, N. (1992). A era dos direitos. Rio de Janeiro: Campus.

Castoriadis, C. (1982). A instituição imaginária da sociedade. Rio de Janeiro: Paz e Terra.

Fischmann, R. (1998). Estratégias de superação da discriminação étnica e religiosa no Brasil. In P. S. Pinheiro \& S. P. Guimarães (Orgs.), Direitos Humanos no Século XXI (pp. 959-985). Brasília, DF: Ministério das Relações Exteriores/IPRI.

Fischmann, R. (2001). Educação, direitos humanos, tolerância e paz. Paidéia-Cadernos de Psicologia e Educação, 11(20), 67-77.

Goffman, E. (1988). Estigma: Notas sobre a manipulação da identidade deteriorada. Rio de Janeiro: Guanabara.

Habermas, J. (1975). Ciência e técnica como ideologia (Os Pensadores, Vol. 48). São Paulo: Abril Cultural.
Kelman, H.C. (1973). Violence without moral restraint: Reflections on the dehumanization of victims and victimizers. Journal of Social Issues, 29(4), 25-61.

Kelman, H. C., \& Hamilton, V. L. (1989). Crimes of obedience: Toward a social psychology of authority and responsibility. New Haven, CT: Yale University Press.

Lafer, C. (1988). A reconstrução dos direitos humanos. São Paulo: Companhia das Letras.

Lorenz, K. (1988). A demolição do homem: Crítica à falsa ideologia do progresso. São Paulo: Brasiliense.

Marcuse, H. (1982). A ideologia da sociedade industrial: O homem unidimensional (6a ed.). Rio de Janeiro: Zahar.

Moore-Jr, B. (1987). Injustiça: As bases sociais da obediência e da revolta. São Paulo: Brasiliense.

Weber, M. (1982). Ensaios de Sociologia (5a ed.). Rio de Janeiro: Guanabara.

Artigo recebido em 17/12/2006.

Aceito para publicação em 15/07/2007.

Endereço para correspondência:

Roseli Fischmann. Av da Universidade, 308. CEP:05508-900, São Paulo-SP.E-mail: roselif@usp.br

Roseli Fischmann é Professora Titular da Faculdade de Educação da Universidade de São Paulo, docente do Programa de Pós-graduação em Educação desta instituição. 